\title{
ARTÍCULOS
}

\section{La Educación Informal de Pedro y su Percepción de la Mujer: una Historia de Vida}

\section{Pedro's Informal Education and his Perception of Women:}

\section{a Life Story}

\section{RESUMEN:}

Heydi Melissa Peréz De la Cruz

Yoselin Johana Merida Trujillo Universidad Autónoma de Chiapas heydimelissa19@gmail.com yosmetru15@gmail.com

El propósito de este texto es dar a conocer qué factores de la educación informal de un individuo influyen en la percepción hacia la mujer. Este artículo está centrado en la historia de vida de Pedro Hernández ${ }^{1}$ un joven de 22 años, estudiante de la 1 Licenciatura de Pedagogía en la Universidad Autónoma de Chiapas (UNACH). Se describe la percepción que tiene de la mujer, cómo ha sido la educación que recibió en su hogar a lo largo de su vida, y por último las opiniones, pensamientos, conductas y actitudes afectivas de Pedro hacia la mujer.

Palabras Clave: Educación informal, percepción, género, machismo, estereotipos.

\section{ABSTRAC:}

The purpose of this text is to make known what factors of the informal education of the individual influence the perception of women. This article is centered on the life story of Pedro Hernández, a 22 years old young man, student of the Bachelor of

\footnotetext{
${ }^{1}$ Nombre ficticio, se conserva la identidad.
} 
| Cuatrimestral Facultad de Humanidades Campus VI

Reserva de Derechos al Uso Exclusivo No.: 04-2018-060814012200-203| ISSN: 2594-1755

Año III | Número 9 | Mayo - Agosto 2020

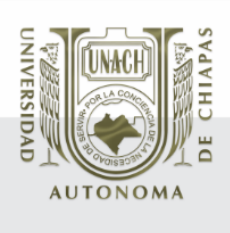

\section{ARTÍCULOS}

Pedagogy at the Autonomous University of Chiapas (UNACH). The perception that he has of the woman is described, how the education he received in his home has been throughout his life, and finally Pedro's opinions, thoughts, behaviors and affective attitudes towards women.

Keywords: Informal education, perception, gender, machismo, stereotypes.

\section{INTRODUCCIÓN:}

Este artículo es resultado de un proyecto de investigación que terminó en un proyecto de tesis que fue presentado en 2020 y da cuenta de temas sobre género y educación informal, estos dos temas se cruzan para conocer las percepciones que se generan acerca de la mujer con respecto de la educación informal que se recibe, se realizó una historia de vida que da cuenta de diversas etapas y momentos en la vida de Pedro en las que da muestra de la realidad que se vive en la sociedad mexicana patriarcal que deviene en distas formas de ejercer un sistema machista aún afecta en gran medida a las mujeres.

La mujer ha sido desvalorizada a lo largo de la historia y actualmente sigue la violencia hacia la mujer, la consecuencia más extrema es la muerte, este acto es denominado feminicidio.

El ideal de la sociedad implica que tanto hombres como mujeres tienen el mismo valor entonces ¿por qué forman al sujeto haciéndole creer que la mujer es inferior al hombre e incluso que el hombre tiene derecho sobre la mujer? Estas percepciones han llevado a la mujer a situaciones de peligro, en México se han

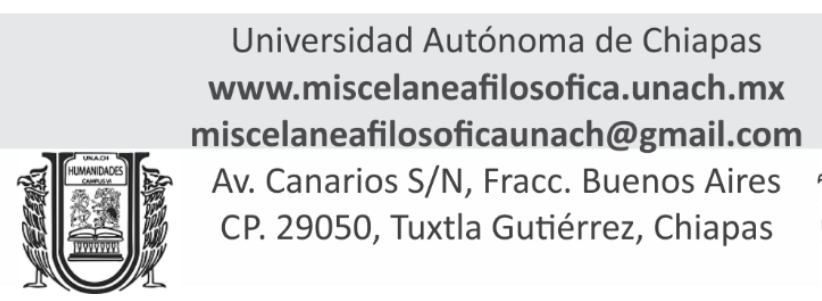


| Cuatrimestral Facultad de Humanidades Campus VI Reserva de Derechos al Uso Exclusivo No.: 04-2018-060814012200-203| ISSN: 2594-1755 Año III | Número 9 | Mayo - Agosto 2020

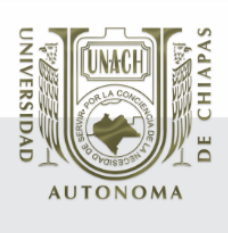

\section{ARTÍCULOS}

Así se refleja la ideología de muchas familias, acerca de los roles del hombre y la mujer, se han inculcado tanto estas costumbres que son asimiladas por la sociedad y cuando alguien opina lo contrario se comienza a crear un conflicto de ideologías.

Estas ideologías dentro de la familia tienen mucha influencia en la crianza de los individuos, los padres son quienes forman a los hijos, y esta formación es de acuerdo con las creencias que tienen, por ejemplo, si los padres piensan que la mujer únicamente debe de estar en el hogar y el hombre es quien debe de sustentar a la familia, estas creencias posiblemente van a ser repetidas por los hijos.

La educación informal es el principal ámbito que forma a los seres humanos, en valores, conductas, ideologías etcétera. Por lo tanto, es importante estudiar este fenómeno a través de esta investigación que permita mostrar, cómo ha influido la formación informal de Pedro en su percepción de la mujer.

\section{Educación informal}

La educación es uno de los elementos más importantes a lo largo de la vida del ser humano, quien de manera cotidiana se encuentra en constante aprendizaje, por tanto, se considera un factor esencial para su desarrollo. La educación es un proceso involucra a la sociedad en su conjunto, por medio del cual se forman valores, experiencias, conductas, pensamientos, costumbres, hábitos etcétera, que contribuyen al desarrollo de las distintas facultades, capacidades y destrezas que como individuos se necesitan. 
| Cuatrimestral Facultad de Humanidades Campus VI Reserva de Derechos al Uso Exclusivo No.: 04-2018-060814012200-203| ISSN: 2594-1755 Año III | Número 9 | Mayo - Agosto 2020

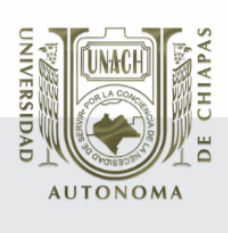

\section{ARTÍCULOS}

Así, la educación, no obstante, su cotidianidad en la vida de las personas es un proceso complejo, que se da desde diferentes etapas de la vida del ser humano y de diferentes formas ya sea de manera formal, no formal o informal. Para este artículo es importante resaltar a la educación informal, este tipo de educación se da principalmente en el núcleo familiar, y es el primer ámbito de aprendizaje del individuo, es donde se desarrolla $\mathrm{y}$, por ende, donde aprende los primeros conocimientos.

Toda acción del ser humano contribuye a un aprendizaje, desde que el individuo llega al mundo, va adquiriendo todo tipo de información, la interacción entre pares contribuye al crecimiento del aprender a ser, y la personalidad evoluciona día con día, Pacheco (2007) hace referencia a que la educación informal no es más que un proceso que dura toda la vida, es decir, el ser humano está inmerso en una sociedad llena de costumbres, religiones, tradiciones, cultura, etcétera, y todo este contexto social que lo rodea, son contextos inmediatos del sujeto, es decir, forma parte del mismo, infieren en su proceso de enseñanzaaprendizaje, y sirve como un instrumento de transmisión y contagio de información e imitación de conductas.

El sujeto se va formando de acuerdo a su contexto y todas las experiencias que se le presentan en su vida. Por lo tanto, la educación es un proceso social, donde se forman los pensamientos, conductas, formas de ver y ser en la vida. 


\section{ARTÍCULOS}

\section{Concepto de familia}

La familia está compuesta por personas más cercanas al sujeto, como los padres, hermanos, tíos, etcétera, es el núcleo donde el individuo empieza el proceso de formación y donde adquiere ciertos aspectos como creencias, valores, conductas y actitudes. Para Chavarría (2004) “La familia es la instancia educativa primaria; donde se inicia el proceso de perfeccionamiento de todas las facultades específicamente humanas, y por ello, el ámbito natural para nacer, crecer y morir como personas" (p. 150).

La familia es parte fundamental de la formación del sujeto, es el primer contexto donde se interactúa, parte de lo que el individuo es, es gracias a esta institución llamada familia, conformada por padres, hermanos, tíos, abuelos, hijos, y demás. Según Lever (1999) dice que:

En el seno de la familia es donde el niño internaliza los primeros patrones de conducta, normas y valores que le permitirán interactuar con otros miembros de su familia y su comunidad y, posteriormente en la escuela, aprenderá patrones de carácter más universalista que le servirán para integrarse a la sociedad de la que forma parte. (párr. 5).

Las primeras personas con quienes se tiene contacto son con los padres, desde que el niño nace ellos se encargan de cuidar y posteriormente de enseñar lo básico de la vida: a comer, bañarse, vestirse etcétera, pero también enseñan ciertos valores que ellos consideran esenciales. Parte del desenvolvimiento que el niño tenga en la familia va a influir en sus próximas relaciones en otro contexto.

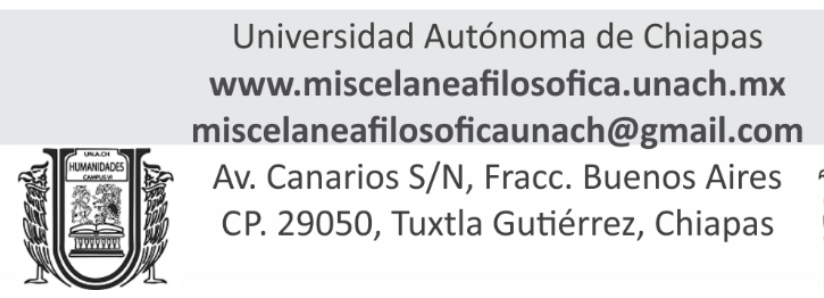




\section{ARTÍCULOS}

\section{Importancia de la Educación Familiar en la Percepción de la mujer}

La percepción de la mujer en la sociedad es un estereotipo construido por el ser humano, donde se percibe a la mujer con actividades "correctas" para su sexo. Esta percepción, no es más que imágenes mentales que se forman a lo largo de la vida, se construyen mediante las experiencias, enseñanzas, contexto, costumbres y demás. De acuerdo con Melgarejo (1994):

La percepción es el proceso cognitivo de la conciencia que consiste en el reconocimiento, interpretación y significación para la elaboración de juicios en torno a las sensaciones obtenidas del ambiente físico y social, en el que intervienen otros procesos psíquicos entre los que se encuentran el aprendizaje, la memoria y la simbolización. (p. 48).

La percepción en el ser humano es un conjunto de procesos y actividades que se forman en el orden social donde éste se desenvuelve, se relaciona con la estimulación de ciertos sentidos, mediante los cuales se obtiene información y conocimiento, acerca de cómo es el sujeto, respecto a su hábitat (todo lo que lo rodea), las acciones que efectúan en éste, y sus propios estados internos. La percepción de las cosas va a depender de cómo ha sido educado el ser humano, qué valores, creencias y costumbres, le han inculcado. Por tal razón, la familia juega un rol importante en la forma de cómo se perciben las cosas, personas o situaciones, es la principal fuente del ser, es decir, quien atribuye conocimientos para aprender a ser. 


\section{Teorías}

El psicólogo Ruso Lev Vygotsky establece en su teoría sociocultural, la importancia del entorno en la que el niño se desarrolla sostiene que el aprendizaje se adquiere por medio de la interacción social. Esta teoría ha sido fundamento en múltiples investigaciones. Esta investigación se centra en la formación informal de Pedro y en su percepción de la mujer, retomando la teoría de Vygotsky, se considera que el contexto social influye en el aprendizaje, por lo tanto, en la formación, por eso esta investigación se fundamenta en la teoría sociocultural, porque el entorno en el que se desarrolla un niño es de primordial importancia, en este caso, el contexto de Pedro durante su infancia y su desarrollo, influyó en su formación y en su percepción en cuanto al sexo femenino.

Así mismo se retoma la Teoría Ecológica de Bronfenbrenner, con el fin de explicar con profundidad cómo el contexto y el ambiente influyen en el desarrollo de conductas actitudes y comportamientos en un sujeto, en este caso para comprender la educación informal de Pedro y cómo ésta influyó en su construcción de su percepción de la mujer. La teoría ecológica se basa en el desarrollo de los individuos a través de los distintos escenarios, contextos, ambientes en los que se ve implicado, Destaca el desarrollo del sujeto en las relaciones familiares, donde el ser humano se encuentra influenciado desde que nace, por las enseñanzas que se le imparten. Aunque la familia es tomada como el principal emisor de la formación del sujeto, no hay que dejar de lado las relaciones entre amigos, escuela, vecinos, comunidad etc. Estos forman parte de su desarrollo y de su habita, e influyen en su forma de ser y estar en el mundo.

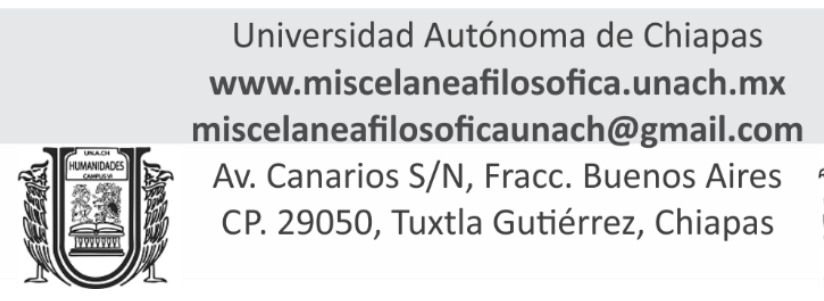




\section{ARTÍCULOS}

\section{Equidad e igualdad}

Equidad e igualdad de género son dos términos muy mencionados en la actualidad, y sobre todo en los diversos movimientos que se han hecho a favor de la mujer. Es importante destacar que estas dos palabras no significan lo mismo.

La equidad de género es un concepto que ha permanecido en la lucha de las mujeres significa dar oportunidades de acuerdo con sus necesidades, más allá de las diferencias físicas. Que los derechos de las mujeres y hombres sean iguales, que exista justicia, tomando en cuenta características del contexto y las necesidades específicas

Es evidente que entre hombres y mujeres existen diferencias, pero lo que se pretende es lograr que haya igualdad en cuanto a la forma de trato, el hombre y la mujer tienen el mismo valor, y ningún sexo debería estar por encima del otro.

Por décadas las mujeres han sido víctimas de la desigualdad, por años han sido desvalorizadas y de alguna forma no se le ha dado la libertad de elegir sobre sí misma, y si lo hace, se le critica y sataniza. Esto no debería de ser así, porque tanto hombres y mujeres son iguales, por lo tanto, deberían de tener las mismas oportunidades, para desarrollarse en el ámbito de preferencia. La desigualdad afecta tanto a hombres como a mujeres, a los hombres también les pesan ciertos estereotipos, por esto la desigualdad de género es tema de todos y no solo la lucha de las mujeres. 


\section{ARTÍCULOS}

\section{Machismo y patriarcado}

El sistema patriarcal y el machismo están relacionados. Al vivir en una sociedad donde el hombre es el protagonista y la mujer es excluida, debido a que históricamente el hombre ha estado en el espacio público y las mujeres en el ámbito privado, se han formado marcadas desigualdades, pero se han perpetuado en la asignación de roles y formas de ser para uno y para otro género. El término machismo hace referencia al sentimiento de superioridad que tiene el género masculino, excluyendo a la mujer, ignorando sus derechos y violentando de forma física y también psicológica. El patriarcado, se refiere a un orden socialmente establecido, donde el hombre es quien tiene el poder dentro de la familia y también fuera. Existe desde hace mucho tiempo, e incluso ha sido aceptado por muchas mujeres, es decir, se ha naturalizado. En este orden existe una dominación del hombre hacia la mujer y esta ideología se ha reproducido a lo largo de la sociedad.

\section{Feminismo y estereotipos}

El pensamiento feminista, ayuda a entender los distintos fenómenos que surgen en contra de la mujer y los distintos movimientos que se han hecho para buscar equidad, justicia y armonía en la sociedad. El movimiento feminista surge a partir de la conciencia en las mujeres, al estar cansadas de tantas situaciones de injusticia, maltrato y violencia, empiezan a revelarse contra el sistema, y sobre los roles establecidos a cada género. Por lo tanto, el feminismo es un movimiento que lucha para exigir el cambio donde haya respeto entre las personas sin importar el sexo,

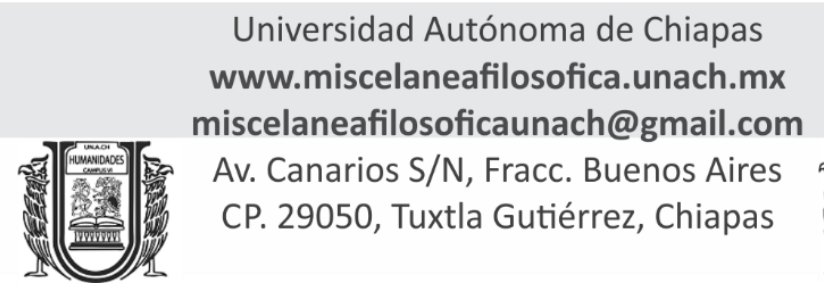




\section{ARTÍCULOS}

que cuestionan a las estructuras de poder que están establecidas dentro de la sociedad.

Los estereotipos de género por su lado, son creencias, modelos e ideas, que caracterizan los típicos roles que se le atribuyen a las mujeres y hombres, esto se debe a que la sociedad mantiene y define qué es lo "adecuado" para cada persona.

La sociedad misma es quien construye y atribuye características a los miembros del grupo que los constituye, todas las personas miembros de cualquier grupo social poseen características o atributos particulares que se van construyendo día con día, esto se debe a que los seres humanos basan su mundo y su forma de ser conforme a todo lo que se observa, es decir, crean imágenes mentales que hacen que actúen de la manera en la que otros lo hacen (personas que lo rodean). Como señala Blanco (2008):

Los estereotipos de género son construcciones culturales que determinan una visión de las características y actitudes de cada sexo. Crean modelos rígidos en los que tienen que encajar para ser socialmente aceptado, fijan un modelo de ser chico y un modelo de ser chica y, a partir de una visión tópica construida, establecen un sistema desigual de relaciones entre los dos sexos y cada uno de ellos hacia el mundo. (p. 226)

Estos estereotipos crean roles asignados a cada sexo, la sociedad va determinando actitudes y características para la mujer y el hombre, muchas veces si no se siguen estos lineamientos, la sociedad no acepta tales conductas, es importante mencionar

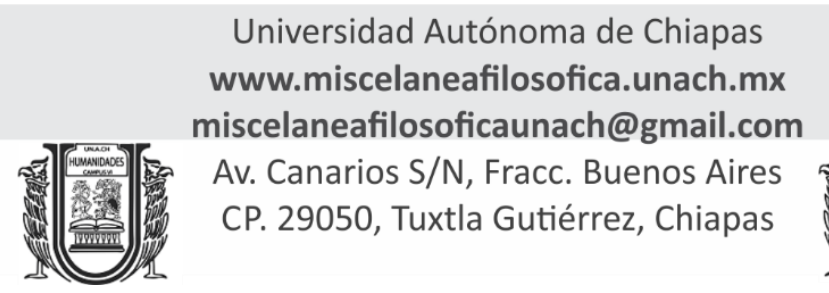


| Cuatrimestral Facultad de Humanidades Campus VI Reserva de Derechos al Uso Exclusivo No.: 04-2018-060814012200-203| ISSN: 2594-1755 Año III | Número 9 | Mayo - Agosto 2020

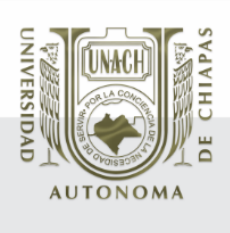

\section{ARTÍCULOS}

hacíamos burla. Si alguien jugaba con las niñas nos reíamos, porque teníamos considerado que las niñas eran más débiles que los niños, por ejemplo, las niñas no jugaban futbol y si jugaban nosotros teníamos que jugar despacio y nos dejábamos meter gol. La verdad yo ya sabía que si me ponía a jugar con ellas se iban a burlar de mí, entonces comencé a creer que jugar con las niñas es algo malo. Si regresara a mi infancia no jugaría con las niñas a la comidita, no me sentiría cómodo, jugaría con mis amigos. Había juegos como la mamá y el papá, pero esos ya eran juegos más chuscos. Lo que más jugábamos los niños del barrio era el fútbol porque el deporte se consideraba el más fuerte. Cuando jugábamos con las niñas era a las agarradas, a la piña, a la cebolla caliente, stop, al avión y a policías y a ladrones (Entrevista con Pedro).

Los estereotipos de género impactan a Pedro desde la infancia, determinando que "los hombres no lloran, porque son los fuertes" una construcción sociocultural que la sociedad normaliza. Pedro escuchó esta frase de amigos y familiares y la asimiló, naturalizando ese pensamiento:

Tengo fracturado el brazo, pero esa no fue una travesura, fue un accidente. Hice una travesura muy chistosa, mi mamá tenía muchos pollos, y en mi casa había muchos árboles, entonces los pollos se subían a ellos, como mi mamá tenía muchas plantas no le gustaba que le cayera popo de gallina, entonces mi mamá optó por colgar una lona de un árbol a otro, entonces todo el popo de gallina caía sobre 
| Cuatrimestral Facultad de Humanidades Campus VI Reserva de Derechos al Uso Exclusivo No.: 04-2018-060814012200-203| ISSN: 2594-1755 Año III | Número 9 | Mayo - Agosto 2020

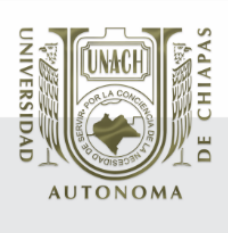

\section{ARTÍCULOS}

esa lona, y como ya había pasado mucho tiempo ya había mucha. Un día estábamos jugando con mi amigo Matías y se nos ocurrió hacer una casa en el árbol, porque veíamos mucha caricaturas y vimos la famosa casa de árbol con ramas y resulta que nos habíamos puesto en una rama, pero con tantos movimientos, la rama no soportó y poco a poco se fue quebrando hasta que llegó a cierto punto que se quebró y pues fuimos a dar con mi amigo Matías a la lona, entonces todo el popó de las gallinas quedó sobre nosotros, y pues no lloramos porque entre nosotros nos íbamos a hacer burla y esa fue mi travesura. Ninguno de los dos lloró, aunque nos dolió mucho, pero no lloramos, porque los niños no lloran, bueno es lo que siempre dicen, cómo vas a llorar si eres niño, para decir que los hombres son un poco más fuertes. Eso lo escuché con amigos y familiares, cuando alguien iba a llorar decían, ya va a llorar la niña y por eso tenías que aguantarte o llorar donde nadie te viera (Entrevista con Pedro).

Los estereotipos de género impactan a Pedro desde la infancia, determinando que "los hombres no lloran, porque son los fuertes" una construcción sociocultural que la sociedad normaliza. Pedro escuchó esta frase de amigos y familiares y la asimiló, naturalizando ese pensamiento:

Tengo fracturado el brazo, pero esa no fue una travesura, fue un accidente. Hice una travesura muy chistosa, mi mamá tenía muchos pollos, y en mi casa había muchos árboles, entonces los pollos se subían a ellos, como mi mamá tenía muchas plantas no le gustaba 
| Cuatrimestral Facultad de Humanidades Campus VI Reserva de Derechos al Uso Exclusivo No.: 04-2018-060814012200-203| ISSN: 2594-1755 Año III | Número 9 | Mayo - Agosto 2020

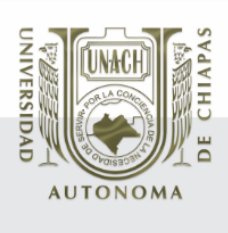

\section{ARTÍCULOS}

que le cayera popo de gallina, entonces mi mamá optó por colgar una lona de un árbol a otro, entonces todo el popo de gallina caía sobre esa lona, y como ya había pasado mucho tiempo ya había mucha. Un día estábamos jugando con mi amigo Matías y se nos ocurrió hacer una casa en el árbol, porque veíamos mucha caricaturas y vimos la famosa casa de árbol con ramas y resulta que nos habíamos puesto en una rama, pero con tantos movimientos, la rama no soportó y poco a poco se fue quebrando hasta que llegó a cierto punto que se quebró y pues fuimos a dar con mi amigo Matías a la lona, entonces todo el popó de las gallinas quedó sobre nosotros, y pues no lloramos porque entre nosotros nos íbamos a hacer burla y esa fue mi travesura. Ninguno de los dos lloró, aunque nos dolió mucho, pero no lloramos, porque los niños no lloran, bueno es lo que siempre dicen, cómo vas a llorar si eres niño, para decir que los hombres son un poco más fuertes. Eso lo escuché con amigos y familiares, cuando alguien iba a llorar decían, ya va a llorar la niña y por eso tenías que aguantarte o llorar donde nadie te viera (Entrevista con Pedro).

Algunas de las actividades que Pedro práctico en la escuela fue el Fútbol y el atletismo, las consideraba "adecuado" para el hombre, el voleibol nunca lo practicó y tampoco le gustó porque lo considera un deporte únicamente para las mujeres, nuevamente clasifica que algunas actividades corresponden a los hombres y otras que pertenecen a las mujeres: 
| Cuatrimestral Facultad de Humanidades Campus VI Reserva de Derechos al Uso Exclusivo No.: 04-2018-060814012200-203| ISSN: 2594-1755 Año III | Número 9 | Mayo - Agosto 2020

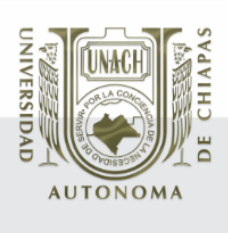

\section{ARTÍCULOS}

En el fútbol nada más y en las carreras de atletismo. El básquetbol no me gustaba porque era para gordos, el voleibol era para las mujeres regularmente, no me gustó el voleibol porque siempre veía que lo jugaban las niñas. Nunca estuve en la escolta ni en la banda de guerra (Entrevista con Pedro).

Para Pedro era muy importante demostrar ser fuerte, constantemente menciona el no querer demostrar sus sentimientos, tenía miedo de hacer lo que le gustaba y que se burlaran de él, las actividades que tenía en mente, era atribuidas como femeninas, por lo cual, Pedro no se atrevía a realizar, solo realizaba actividades que eran consideradas masculinas:

En el fútbol, era muy bueno. Me gustaba la oratoria, pero nunca me animé, me daba pena, porque a veces se ponían a llorar y a pesar de que me gustan los poemas nunca me atreví porque mis amigos se iban a burlar, porque iba a gritar y a llorar. Regularmente participan las niñas, de los niños se burlaban (Entrevista con Pedro).

Al preguntarle a Pedro si sus padres hablaron con él de sexualidad menciona que sus padres nunca hablaron de sexualidad con él. Señala lo que piensa de cómo aprende un hombre acerca del tema de sexualidad, considera que el hombre es independiente en su aprendizaje y que es a la mujer a quien se le debe de enseñar sobre sexualidad:

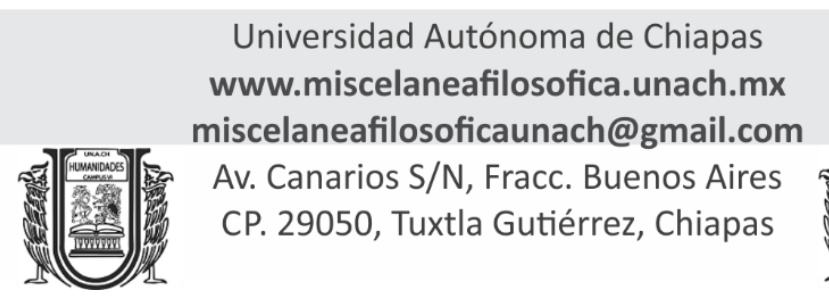




\section{ARTÍCULOS}

La verdad no, nunca hablé con ellos de sexualidad, eso ya lo vi en la secundaria, es algo que te da mucho morbo, y tu mamá espera que tu papá te hable de eso, pero simplemente los papás dicen "para que le digo, supongo que ya lo sabe, o hay lo va a aprender en la escuela". Pero eso siento que es porque soy hombre, porque si hubiera sido mujer, yo creo que, de volada, ya desde la primera regla te explican todo. Pero uno como hombre tiene que aprender solito, bueno yo opino eso, siempre con mis amigos hemos dicho eso (Entrevista con Pedro).

En repetidas ocasiones Pedro señala que la relación con su padre no era tan cercana, entre ellos no había pláticas, sin embargo, se siente muy agradecido con su padre por brindarle todo lo necesario en cuanto a lo económico, porque fue su padre quien se encargó de los gastos en casa, Pedro señala a su Padre como "jefe del hogar", esta ideología se ve reflejada más adelante, ya que define al hombre como el pilar del hogar. Hay muchas cosas que parecen ser insignificantes, sin embargo, todo lo que Pedro percibe de su alrededor, repercute en su aprendizaje y en la percepción de la mujer:

Mi papá es maestro de primaria, bueno ahorita ya es director, trabaja de 7 am a 1 pm, y llega a la casa como a las 4 o 5 pm, siempre está en su escritorio trabajando. No he sido tan cercano a mi papá, mis mejores recuerdos son los viajes que hemos hecho al mar. No jugué con mi papá, no hay muchos recuerdos especiales. La relación con mi papá era un poco buena, solo lo veía en las noches, solo decía ahí está 
| Cuatrimestral Facultad de Humanidades Campus VI Reserva de Derechos al Uso Exclusivo No.: 04-2018-060814012200-203| ISSN: 2594-1755 Año III | Número 9 | Mayo - Agosto 2020

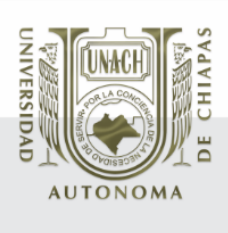

\section{ARTÍCULOS}

mi papá y le daba buenas noches y ya, era un poco digamos no tan amigable, pero si aceptable. No éramos de esos que se sentaban a cenar y preguntaban si cómo le fue hoy, cada uno por su rumbo. No me interesaba, no me sentía atraído en lo que hacía o le pasaba, hasta la fecha no le pregunto cómo le fue en su día. No somos tan confianzudos en ese aspecto, para preguntar cómo le fue. En la adolescencia si plática de las mujeres y así. De mi papá admiro la forma en la que se expresa, en la que habla y se relaciona con las personas, su mentalidad para ser un buen líder. Es muy formal y encuentra las palabras para debatir y argumentar, suele convencer a las personas acerca de un punto de opinión. Le agradezco a mi padre el hecho de ser un buen jefe de familia, el que siempre dio dinero para que tuviéramos lo necesario, no lo lujoso, pero sí lo necesario, como la comida, la educación, vestimenta y salud. Mi mamá trabajaba repostería en la casa, hacia gelatinas y pasteles (Entrevista de Pedro).

Socialmente, a los hombres se les vincula con cualidades como la valentía, el poder, la racionalidad, la fortaleza o la eficacia y a la figura femenina como la fragilidad, la sumisión, debilidad y delicadeza, estas características son construcciones socioculturales que durante años se ha inculcado, se piensa en la mujer como ser inferior. Pedro asegura que fue su madre quien le enseñó que a las mujeres se les trata de forma diferente que, a un hombre, por eso su trato con ellas es especial. Usualmente Pedro distingue el sexo con el tono de voz diferenciado con el que se dirigen sus padres, las maneras de identificar a partir de la vestimenta, la actitud, 
| Cuatrimestral Facultad de Humanidades Campus VI Reserva de Derechos al Uso Exclusivo No.: 04-2018-060814012200-203| ISSN: 2594-1755 Año III | Número 9 | Mayo - Agosto 2020

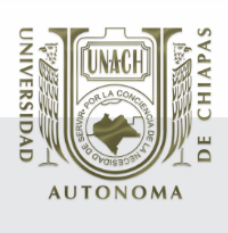

\section{ARTÍCULOS}

los roles entre otras cosas. Por tal razón, Pedro siempre le atribuye a la mujer la delicadeza asociándose con la debilidad:

Siempre he tenido el privilegio de toparme con personas, y conocer un mundo lleno de personas, siempre las he respetado, aún así me caiga mal, me caigan bien, siempre ha existido ese respeto, y más con las mujeres siempre he respetado mucho a las mujeres, no te puedes llevar como te llevas con un hombre a con una mujer, es muy diferente, siempre para mí el respeto es lo principal, es clave esencial para una buena relación con las personas, y la parte empática, pienso que eso es lo que me ha ayudado siempre he invitado a las personas cuando les hace falta algo, siempre he estado ahí, siempre suelo dar detalles, siempre suelo ser un poco emocional y sensible ante algunos sucesos.

Mi mamá siempre me ha inculcado eso, que las mujeres son un poco más delicadas, que tienes que tener un cierto respeto hacia ellas, tanto en lo verbal como en lo físico. Yo nunca he visto que mi papá le haya gritado a mi mamá, ni que se hayan peleado, jamás, quizás lo hacían, pero en otro lugar, pero yo nunca vi eso, esa parte si la aprendí de mi mamá de respetar a las demás personas, de siempre apoyar y ayudar (Entrevista con Pedro)

Al preguntar sobre cómo eran repartidas las tareas domésticas en su familia, Pedro menciona que nunca ayudaba en nada y expresa que su madre "era la empleada de 
| Cuatrimestral Facultad de Humanidades Campus VI

Reserva de Derechos al Uso Exclusivo No.: 04-2018-060814012200-203| ISSN: 2594-1755

Año III | Número 9 | Mayo - Agosto 2020

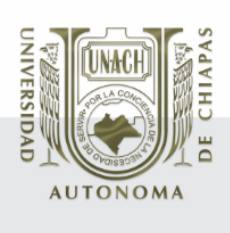

\section{ARTÍCULOS}

mes", refiriéndose a que su madre es quien hace todas las actividades del hogar y es la responsable de mantener la casa limpia:

Mi mamá era la empleada del mes. Que yo recuerde casi no nos la repartimos, la verdad no. Siempre era de que acababas de comer y te salías a jugar. La verdad creo que nunca nos ponían a hacer nada ni a lavar los platos, lavar la ropa o trapear, no se daba eso en sí. Nunca nos mandaban a limpiar. Y si algún día nos lo pidieron no lo hacíamos. Nunca les decíamos a nuestros padres, "que mi hermano haga esto y yo esto", casi no se dio. (Entrevista con Pedro).

Pedro comienza a visualizarse en un futuro de 5, 15 y 25 años. Hace un comentario entre risas, donde cuenta que quiere 3 o 4 hijos y que las mujeres para eso están, para tener hijos. Asegura que es su abuelo quien dice y piensa eso, y él retoma esa frase en su vida:

En 5 años me visualizo con un carro y con las cosas que siempre he querido, con un xbox, con una tele, mis videojuegos y siendo maestro.

En 15 años me visualizo ya con mi familia, casa propia, con dos carros, con dos o tres hijos, o bien los que aguante mi señora, (risas). Como dice mi abuelito para eso están.

Y en 15 años, me visualizo con salud, con mis ahorros por todos los años de trabajo, y tratando de disfrutar la vida un poco más relajada, tratando de no olvidar la vida de adolescente (Entrevista con Pedro).

Pedro define y describe a la mujer. Según explica actualmente entiende que la mujer no solamente es ama de casa y la que está a cargo de los hijos y del hogar, 


\section{ARTÍCULOS}

sin embargo, su percepción no ha cambiado del todo, y las acciones y actitudes que tiene, demuestran también lo que piensa de la mujer. Nuevamente relaciona a la mujer con estereotipos de género que son socialmente arraigados por la sociedad como adecuados:

Creo que siempre nos lo han dicho, desde la iglesia, han dicho que la mujer es tu compañera, que a lo largo de los años tienes que buscarte una mujer para que te cases y las desposes, que tengas hijos y familia. Y a mí a lo largo de la vida y del tiempo, he comprendido que la mujer a veces no es eso no es una ama de casa, va más inclinado a hacer un equipo. Yo definiría a la mujer como persona con la que puedes hacer equipo, una buena compañera o una amiga, pero no como objeto. Y la caracterizaría como no sé, siempre que piensas en la mujer, luego luego se te viene a la cabeza el color rosa, las muñecas, las barbies, cabello largo, uñas bien pintadas y si me tocara describir a una mujer, diría que una mujer es una persona lo contrario de un hombre, con diferentes gustos. Te digo, la mujer se compara más con las barbies, la cocina y esas cosas, y a los hombres con los carros y soldados. Siento que al definir a una mujer la definiría como debilidad y delicadez (Entrevista con Pedro).

Pedro creció en un contexto donde su padre era quien suplió los gastos económicos. Pedro fue construyendo la idea de que el líder de una familia es el hombre, siempre describe a su padre como líder y se describió a sí mismo como un líder también, estas enseñanzas formaron en él la diferenciación entre un hombre y una mujer, por lo tanto, define al hombre de la siguiente manera:

Siempre he dicho que el hombre es el líder de familia, el líder de una casa, el que tiene que darle todo a la mujer, es el máximo pilar de un hogar, y creo que, para mí, para mí sería eso, que el hombre es el pilar de una familia, un hogar o algo mayormente, para mí sería el hombre (Entrevista con Pedro). 


\section{ARTÍCULOS}

Pedro llama a las palabras o expresiones altisonantes como masculinas, menciona que una mujer no debe decir o tratar con ese tipo de palabras y que solo los hombres pueden hacerlo, expresa que cuando una mujer suele hablar así, él les dice que le hablen bien. Una vez más, describe a la mujer y el hombre relacionando a cada uno con actitudes distintas, y caracteriza al hombre como fuerte, agresivo, brusco y a la mujer como sensible.

Con las mujeres he evitado decir y que me digan palabras como ¡hey wey! o, otros aspectos masculinos, no sé, no me siento cómodo con que ellas me digan hey wey o yo a ellas. De un hombre lo tolero porque es una forma en la que te sueles llevar, pero con una mujer no tolero que me diga esas palabras, pero ya les digo si me quieres hablar, hablame bien y si no pues no, no pasa nada. Pero si yo no tolero mucho eso.

Los hombres suelen tener un carácter más fuerte, un poco más agresivo y las mujeres un poco más sensibles, el hombre suele ser un poco brusco, un poco grosero, y la mujer no tanto. Bueno, algunas sí, pero yo no he conocido a ninguna así (Entrevista con Pedro).

Durante la investigación Pedro atribuye ciertas actividades y características a la mujer y otras específicamente a los hombres, con la vestimenta sucede lo mismo, menciona que para la mujer existe una forma de vestir y para el hombre otra muy diferente, cuando una mujer usa prendas que supuestamente él pertenece a los hombres, las llama de forma despectiva. Pedro comenta que ha llamado a algunas mujeres machorras cuando son "poco femeninas". En repetidas ocasiones Pedro describe a la mujer como frágil y delicada, y al hombre como fuerte:

Creo que todo el mundo alguna vez ha definido a una mujer así, las

llamamos machorras, machorritas. Y ya decimos: "ha mira esa 
| Cuatrimestral Facultad de Humanidades Campus VI Reserva de Derechos al Uso Exclusivo No.: 04-2018-060814012200-203| ISSN: 2594-1755 Año III | Número 9 | Mayo - Agosto 2020

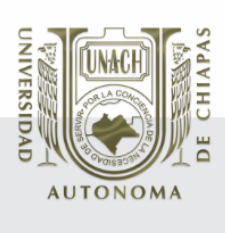

\section{ARTÍCULOS}

La crianza de Pedro estuvo a cargo de su madre, ella fue quien lo cuidó, por lo tanto, quien lo educó, el padre de Pedro estuvo ausente, debido a su trabajo. Pedro es una persona muy apegada a su madre, con su padre no mantiene una relación tan cercana.

Según Pedro, sí existen juguetes propios de niños y otros de niñas. y al narrar su historia de vida, demuestra que él jugaba con carros y soldados, por lo contrario, señala que los muñecos de max steel no le gustaban, porque se asemejan a las muñecas que son para niñas, demostrando el temor de que lo comparen con una niña. De igual manera Pedro sigue patrones y estereotipos establecidos en la sociedad, por ejemplo, dice que el fútbol es para los hombres y el voleibol para niñas. Es interesante que Pedro en repetidas ocasiones describe a la mujer como débil, incluso durante su infancia al jugar con niñas, señala que no era tan brusco con ellas y que cuando jugaba con ellas se dejaba ganar, esto porque inconscientemente Pedro desde su infancia creció con la idea de que la mujer es débil y delicada.

Los estereotipos de género impactan a Pedro desde su infancia, él escuchó de algunos familiares y amigos, la frase - los hombres no lloran, porque son fuertes, por lo tanto, él internalizó esa creencia y no lloraba, al menos frente a los demás, porque asegura que, si lo hacía, le hacían burlas como - ya va a llorar la niñall, prefiriendo entonces no llorar a ser comparado con una niña, como si esto fuera algo vergonzoso. 


\section{ARTÍCULOS}

\section{Referencias bibliográficas}

Chavarria, M. (2004). Educación en un mundo globalizado. Retos y tendencias del proceso educativo. México: Editorial Trillas.

Lamas, M. (2007). El género es cultura. V Campus de Cooperación Cultural. Recuperado de: http://repositorio.ciem.ucr.ac.cr/bitstream/123456789/157/ 1/RCIEM138.pdf

Lamas, M. (1986). La antropología feminista y la categoría" género".Nueva antropología, $8(30)$.

Lamas, M. (1996). La perspectiva de género. Revista de Educación y Cultura de la sección, 47.

Landsheere, V. (1992). La educación y la formación., Buenos Aires: Editorial Docencia.

Lever, J. P., y Jiménez, A. M. (1999). Relación entre la escolaridad y la percepción del funcionamiento familiar.Revista mexicana de investigación educativa, vol 4. Recuperado de: http://www.quadernsdigitals. net/datos_web/hemeroteca/r_54/nr_593/a_8125/8125.pdf

Whittemore, R .; Chase, S. K. y Mandle, C. L. (2001). Validez en la investigación cualitativa. Investigación cualitativa en salud, 11 (4). 